\title{
UHPLC-PDA-ESI-TOF/MS metabolic profiling and antioxidant capacity of arabica and robusta coffee silverskin: Antioxidants vs phytotoxins
}

\author{
Alessia Panusa $^{\mathrm{a}, *}$, Rita Petrucci ${ }^{\mathrm{b}}$, Roberto Lavecchia ${ }^{\mathrm{c}}$, Antonio Zuorro ${ }^{\mathrm{c}}$ \\ a Dipartimento del Farmaco, Istituto Superiore di Sanità, Viale Regina Elena 299, I-00161 Rome, Italy \\ b Dipartimento di Scienze di Base e Applicate per l'Ingegneria SBAI, Sapienza Università di Roma, Via del Castro Laurenziano 7, I-00161 Rome, Italy \\ c Dipartimento di Ingegneria Chimica Materiali Ambiente ICMA, Sapienza Università di Roma, Via Eudossiana, 18, I-00184 Rome, Italy
}

\section{A R T I C L E I N F O}

\section{Keywords:}

Coffee silverskin

Chlorogenic acids

Antioxidant capacity

Atractyligenin derivatives

Furokauranes

UHPLC-PDA-ESI/TOF/MS metabolic profiling

\begin{abstract}
A B S T R A C T
A deeper knowledge of the chemical composition of coffee silverskin (CS) is needed due to the growing interest in its use as a food additive or an ingredient of dietary supplements. Accordingly, the aim of this paper was to investigate the metabolic profile of aqueous extracts of two varieties of CS, Coffee arabica (CS-A), Coffee canephora var. robusta (CS-R) and of a blend of the two (CS-b) and to compare it to the profile of Coffee arabica green coffee (GC). Chlorogenic acids, caffeine, furokauranes, and atractyligenins, phytotoxins not previously detected in CS, were either identified or tentatively assigned. An unknown compound, presumably a carboxyatractyligenin glycoside was detected only in GC. Caffeine and chlorogenic acids were quantified while the content of furokauranes and atractyligens was estimated. GC and CS were also characterized in terms of total polyphenols and antioxidant capacity. Differences in the metabolites distribution, polyphenols and antioxidant capacity in GC and CS were detailed.
\end{abstract}

\section{Introduction}

In the last decades, coffee has been widely recognized as an important source of antioxidants and radical scavengers, with increasing evidence supporting its health-promoting potential (Brezova, Slebodova, \& Stasko, 2009). Many of these benefits are ascribed to a class of phenolic compounds contained in high amount in coffee beans and formed by esterification of quinic acid with hydroxycinnamic acids, hereafter generically termed chlorogenic acids (CGAs) (Mullen et al., 2011; Vignoli, Bassoli, \& Benassi, 2011). For this reason, the consumption of green coffee (GC) extracts, a very rich source of CGAs, is increasing worldwide (Alves et al., 2010).

Coffee is one of the most widely consumed beverages in the world (Choi \& Curhan, 2007) and this has prompted the interest of researchers in the possible use of coffee wastes, such as spent coffee grounds (SCG) and coffee silverskin (CS). Literature on SCG has greatly increased in the last few years, showing that the high content of caffeine (CAF) and CGAs makes them highly attractive as a source of CGAs (Panusa, Zuorro, Lavecchia, Marrosu, \& Petrucci, 2013; Zuorro \& Lavecchia, 2012).

At the same time, there is a growing interest in the valorization of CS, the major by-product of coffee roasting, consisting of the thin tegument covering the coffee beans. Such an interest is mainly due to its richness in polyphenols, caffeine content and total antioxidant capacity of Coffea arabica silverskin (CS-A) (Bresciani, Calani, Bruni, Brighenti, \& Del Rio, 2014; Regazzoni et al., 2016).

The chemical composition of CS-A, in particular the content of dietary fiber (DF), carbohydrates, proteins, free phenols and fats has been analyzed. CS should be considered a valuable functional ingredient due to the high amount of total DF (especially soluble DF) and the low amount of fats and reducing carbohydrates (Borrelli, Esposito, Napolitano, Ritieni, \& Fogliano, 2004). Recently, CS has been used to improve the formulation of biscuits (Garcia-Serna, Martinez-Saez, Mesias, Morales, \& del Castillo, 2014). Furthermore, a novel antioxidant beverage for body weight control based on CS has been proposed for inclusion in the diet of patients with obesity and diabetes due to its low glucose content (Martinez-Saez et al., 2014). Moreover, CS has been investigated as a possible cosmetic ingredient (Rodrigues, Sarmento, Amaral, \& Oliveira, 2016; Rodrigues et al., 2015) and its anti-aging properties and potential for improving skin health have recently been described (Iriondo-DeHond et al., 2016).

On the other hand, the natural occurrence of ochratoxin A (OTA) in green and roasted coffee beans, as well as in CS has been demonstrated (Napolitano, Fogliano, Tafuri, \& Ritieni, 2007). Recently, the presence of several mycotoxins in dietary supplements containing GC extracts has been evaluated. The results have clearly emphasized the necessity

\footnotetext{
* Corresponding author

E-mail address: alessia.panusa@iss.it (A. Panusa).
} 


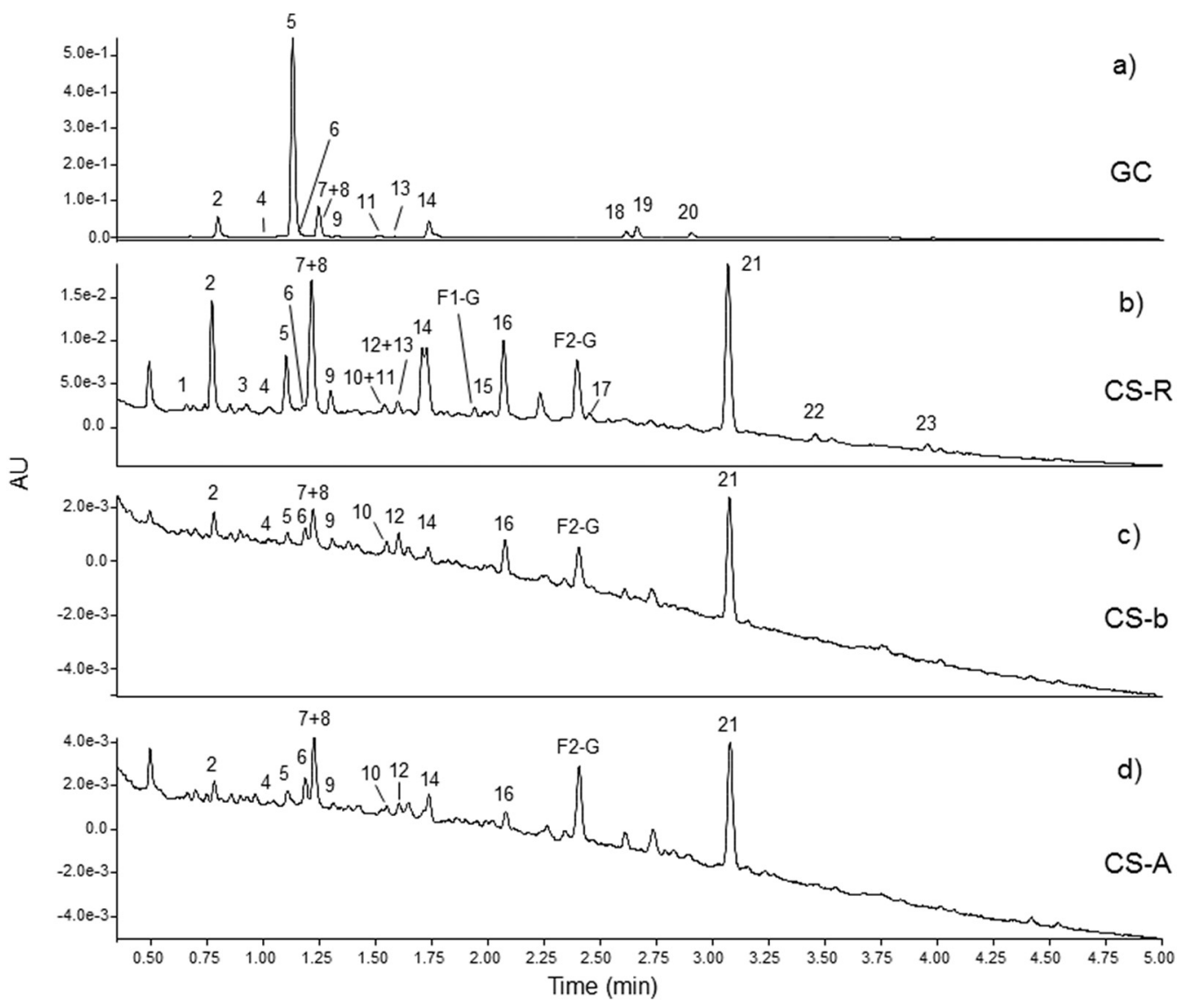

Fig. 1. PDA chromatograms $(\lambda=324 \mathrm{~nm})$ of aqueous extracts of GC (a), CS-R (b), CS-b (c) and CS-A (c).

Table 1

Retention time (RT, min), molecular formula and deprotonated molecule $[\mathrm{M}-\mathrm{H}]^{-}(\mathrm{m} /$ z) of CGAs tentatively assigned in aqueous extracts of GC and CS.

\begin{tabular}{lllll}
\hline Peak & RT & Compound & Molecular formula & {$[\mathrm{M}-\mathrm{H}]^{-}$} \\
\hline 1 & 0.67 & CQA & C16H18O9 & 353.0873 \\
2 & 0.79 & 3-CQA & C16H18O9 & 353.0873 \\
3 & 0.92 & CQA & C16H18O9 & 353.0873 \\
4 & 1.07 & CoQA & C16H18O8 & 337.0923 \\
5 & 1.13 & 5-CQA & C16H18O9 & 353.0873 \\
6 & 1.19 & CAF $^{\text {a }}$ & C8H10N4O2 & {$[\mathrm{M}+\mathrm{H}]^{+} 195.0882$} \\
7 & 1.23 & 4-CQA & C16H18O9 & 353.0873 \\
8 & 1.23 & FQA & C17H20O9 & 367.1029 \\
9 & 1.30 & CA & C9H8O4 & 179.0344 \\
10 & 1.54 & FQA & C17H20O9 & 367.1029 \\
11 & 1.54 & CoQA & C16H18O8 & 337.0923 \\
12 & 1.60 & FQA & C17H20O9 & 367.1029 \\
13 & 1.60 & CoQA & C16H18O8 & 337.0923 \\
14 & 1.71 & FQA & C17H20O9 & 367.1029 \\
15 & 1.94 & di-MeCiQA & C18H22O9 & 381.1186 \\
16 & 2.07 & FA & C10H10O4 & 193.0501 \\
17 & 2.45 & di-MeCiQA & C18H22O9 & 381.1186 \\
18 & 2.61 & di-CQA & C25H24O12 & 515.1190 \\
19 & 2.66 & di-CQA & C25H24O12 & 515.1190 \\
20 & 2.89 & di-CQA & C25H24O12 & 515.1190 \\
21 & 3.07 & di-MeCiA & C11H12O4 & 207.0657 \\
22 & 3.55 & CTF & C20H18N2O5 & 365.1137 \\
23 & 3.96 & CoTF & C20H18N2O4 & 349.1188 \\
\hline
\end{tabular}

${ }^{\mathrm{a}}$ Identified with reference compound.

of monitoring the quality of these products of large consumption and the need to perform accurate toxicological tests (Vaclavik, Vaclavikova, Begley, Krynitsky, \& Rader, 2013). The characterization of CS, particularly in terms of the presence of OTA and phytosterol oxidation products, was also reported and their significant amount in CS-related products might represent a risk for human health (Toschi, Cardenia, Bonaga, Mandrioli, \& Rodriguez-Estrada, 2014).

Recently, concern has been expressed about the consumption of GC and dietary supplements based on raw coffee, due to the presence of atractyligenin and its derivatives, which are structurally related to the phytotoxin atractyloside. Evaluation of their toxic activity showed that three compounds were capable of inhibiting the activity of adenine nucleotide translocase in mitochondria. Among them, 2-O- $\beta$-glucopyranosyl-carboxyatracyligenin exhibited the highest toxicity (Lang et al., 2013; Lang et al., 2014). As a consequence, in a recent review on the chemical composition of CS, the authors speculated about the presence of atractyligenins also in this material (Narita \& Inouye, 2014). Although these compounds should be degraded during the roasting process, the roasting temperature could be not sufficient to achieve complete degradation. This hypothesis is supported by the evidence that chlorogenic lactones, which are formed during the roasting process, were not detected in CS (Regazzoni et al., 2016).

Despite the growing interest in CS as a food additive or an ingredient of dietary supplements, a study on the metabolic profile of CS is lacking. A deeper knowledge of the chemical composition of CS is therefore required in order to evaluate advantages and risks related to its consumption. Accordingly, the aim of the present work was to assess an UHPLC-PDA-ESI-TOF/MS metabolic profile of aqueous extracts of CS with special attention to the presence of atractyligenin derivatives and other metabolitesnot previously investigated in CS.

In order to obtain a comprehensive metabolic profile, CS of the two main coffee varieties, i.e. Coffea arabica (CS-A) and Coffea canephora var. robusta (CS-R) as well as a blend of the two varieties (CS-b) were analyzed. As analytical standards of atractyligenins are not available, aqueous extracts of Arabica GC were used for comparison. Chlorogenic acids, caffeine, furokauranes and phyototoxins were identified or tentatively assigned and their contents in both varieties were compared 

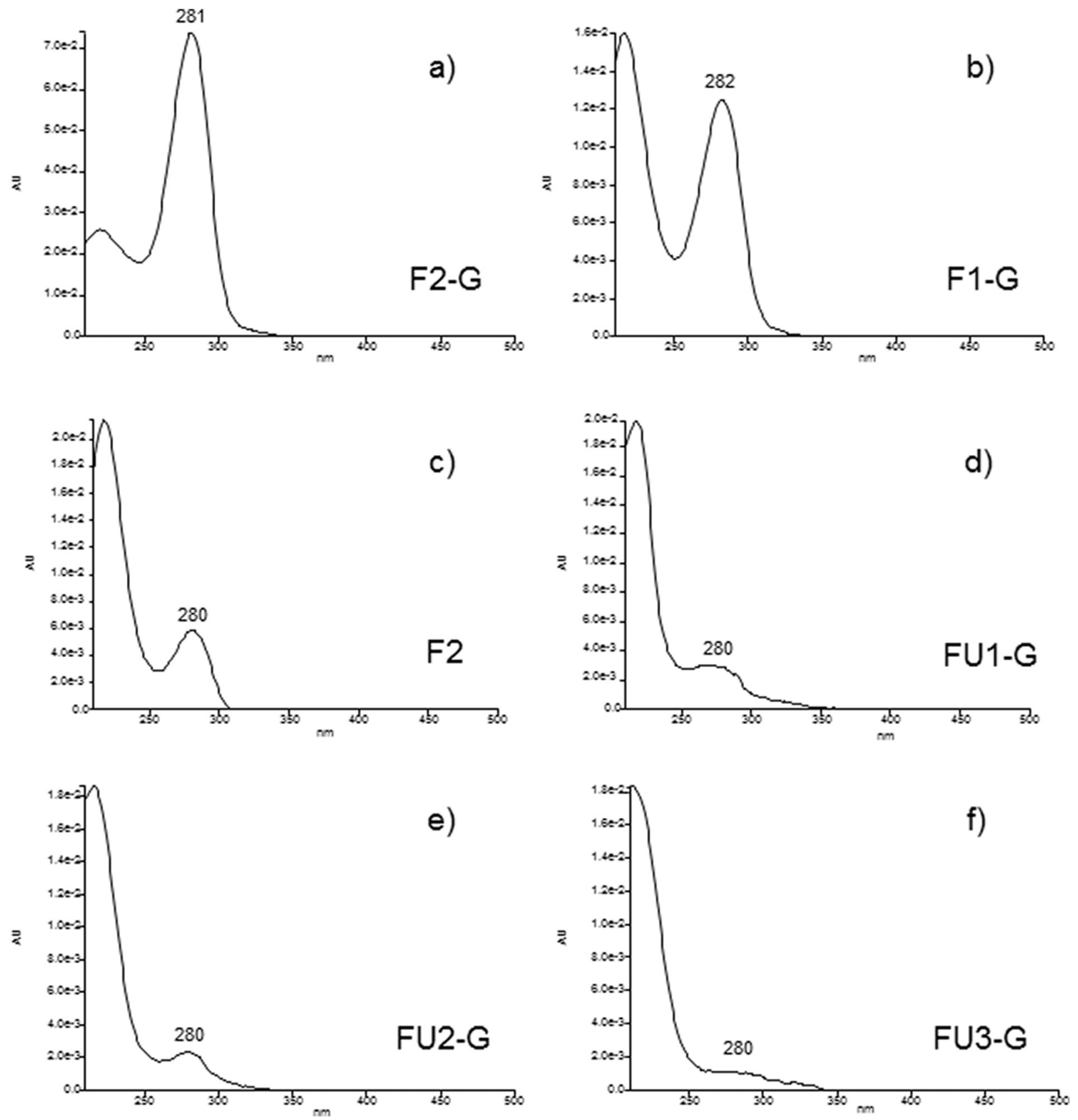

Fig. 2. UV spectra of furokauranes in CS-A extracts: F2-G, mozambioside (a); F1-G, mascaroside (b); F2, mozambioside aglycone (c); FU1-G (d); FU2-G (e); FU3-G (f).

to that of aqueous extracts of Coffea arabica GC. CS-A, CS-R and CS-b were also characterized in terms of total polyphenols, and antioxidant capacity. Based on the results obtained in the present study, the use of CS as a food ingredient or a dietary supplement should be carefully reevaluated, particularly in light of the presence of phytotoxins and the low amount of antioxidants.

\section{Materials and methods}

\subsection{Reagents and solvents}

Ethanol, hydrochloric acid ( $37 \% \mathrm{w} / \mathrm{w})$, sodium carbonate and ferric chloride $\left(\mathrm{FeCl}_{3} \cdot 6 \mathrm{H}_{2} \mathrm{O}\right)$ were purchased from Carlo Erba (Milano, Italy). The Folin-Ciocalteu's phenol reagent, DPPH (2,2-diphenyl-1-picrylhydrazyl) radical, ABTS (2,2-azino-bis-3-ethylbenzothiazoline-6-sulfonic acid), TPTZ (2,4,6-Tri(2-pyridyl)-s-triazine), Trolox (6-hydroxy-2,5,7,8tetramethylchroman-2-carboxylic acid), potassium persulfate $\left(\mathrm{K}_{2} \mathrm{~S}_{2} \mathrm{O}_{8}\right)$, leucine enkephalin, gallic acid, caffeine (CAF), caffeic acid (CA), ferulic acid (FA) and 5-caffeoylquinic acid (5-CQA) were obtained from SigmaAldrich (Milano, Italy). Formic acid (98\%) was purchased from J.T. Baker Chemical Co. All chemicals were reagent grade and used without further purification. Hypergrade acetonitrile for LC-MS was obtained from Merck (Damstadt, Germany) and HPLC grade methanol from Sigma-Aldrich. HPLC-grade water was prepared with a Direct-Q ${ }^{\circledast} 3$ (Millipore, Vimodrone, Italy) water purification system.

\subsection{GC and CS samples preparation and characterization}

GC and CS were obtained from local coffee-roasting companies in Rome (Italy). GC beans were of Coffea arabica variety, while CS was of three different types, derived from the roasting of Coffea arabica (CS-A), Coffea canephora var. robusta (CS-R) and a blend of 75\% $(w / w)$ Arabica and $25 \%$ Robusta (CS-b). All the materials were finely powdered with an electric grinder (Moulinex, Italy) and stored in the dark at room temperature until use. Moisture content was determined by oven drying at $105{ }^{\circ} \mathrm{C}$ to constant weight. 


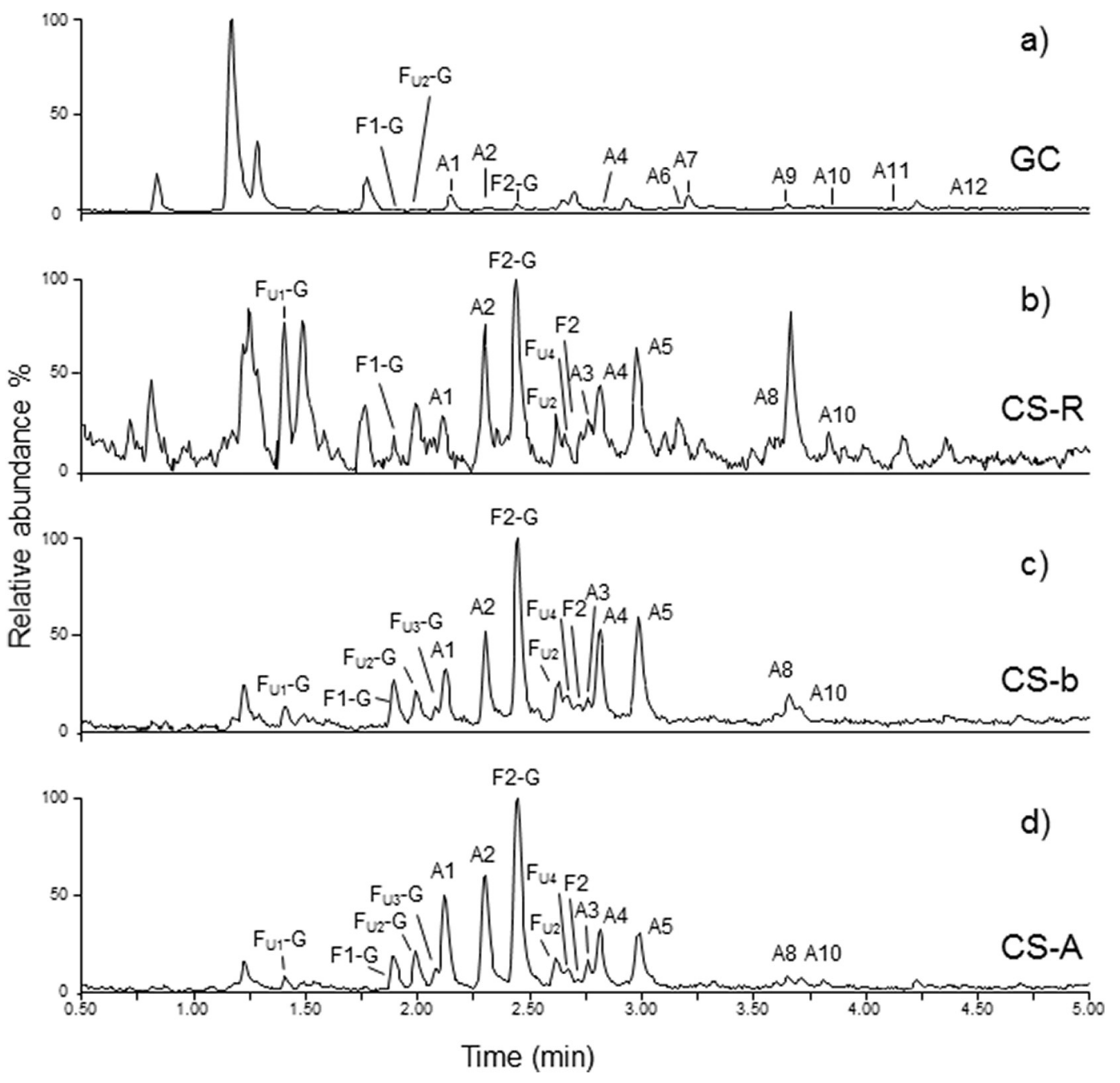

Fig. 3. TIC (nESI) of aqueous extracts of GC (a), CS-R (b), CS-b (c) and CS-A (d).

Extracts from GC and CS were prepared as described in a previous paper (Zuorro, 2015) by contacting a known amount of the ground material ( $0.5 \mathrm{~g}$ GC or $1 \mathrm{~g} \mathrm{CS}$ ) with $50 \mathrm{~mL}$ of distilled water in magnetically stirred flasks at $60{ }^{\circ} \mathrm{C}$ for $30 \mathrm{~min}$. After this time, an aliquot of liquid was withdrawn, filtered at $0.45 \mu \mathrm{m}$ and assayed for phenolic compounds and antioxidant capacity.

\subsubsection{Total phenolic compounds}

Total phenolics were determined by the Folin-Ciocalteu's method following the procedure of Singleton, Orthofer, LamuelaRaventos, \& Packer, 1999 with some modifications already described (Panusa et al., 2013). Total phenolics were calculated from a calibration curve obtained with gallic acid and expressed as gallic acid equivalents (GAE) per dry weight of solid.

\subsubsection{Antioxidant capacity}

Antioxidant capacity was determined by the DPPH, ABTS and FRAP (Ferric Reducing Antioxidant Power) methods. The DPPH assay was previously described (Panusa et al., 2013).

Measurements by the ABTS and FRAP methods were performed according to the procedures described elsewhere (Conde et al., 2009). Antioxidant capacity values determined from the three assays were calculated as percentage of inhibition relative to the control and expressed as Trolox equivalents (TE) per dry weight of solid.

\subsection{UHPLC-PDA-ESI-TOF/MS instrumental conditions}

Chromatographic analyses were performed with a Waters Acquity UPLC $^{\mathrm{TM}}$ system (Milford, MA, USA) equipped with a binary pumping system, an autosampler with thermostat control set at $10^{\circ} \mathrm{C}$, a high temperature column heater set at $30^{\circ} \mathrm{C}$ and a photodiode array (PDA) detector.

A Waters Acquity BEH C18 $(50 \times 2.1 \mathrm{~mm} \mathrm{ID,} 1.7 \mu \mathrm{m})$ analytical column was used for chromatographic separations carried out as previously described (Panusa et al., 2013). The PDA detector was set to scan in the $210-500 \mathrm{~nm}$ range with a frequency of $20 \mathrm{~Hz}$.

The Acquity UPLC ${ }^{\mathrm{TM}}$ system was coupled with a high-resolution Waters Micromass LCT Premier XE time-of-flight (TOF) mass spectrometer (MS) with an electrospray ionization (ESI) source. Data were acquired in negative (nESI) and positive (pESI) ionization and centroid modes in the mass-range $m / z 100-1000$; the analyzer was in W mode with a scan time of $0.2 \mathrm{~s}$ and dynamic range enhancement was enabled. A solution of leucine enkephalin as lock mass $\left(\mathrm{C} 12[\mathrm{M}-\mathrm{H}]^{-}\right.$at $\mathrm{m} / \mathrm{z}$ 554.2615 and $\mathrm{C} 12[\mathrm{M}+\mathrm{H}]^{+}$at $\left.m / z 556.2771\right)$ at the concentration of $2 \mu \mathrm{gmL}^{-1}$ was infused through the lock spray ion source at a flow rate of $5 \mu \mathrm{Lmin}^{-1}$. The lock spray frequency scan was set at 50 . Resolution calculated at $[\mathrm{M}-\mathrm{H}]^{-} \mathrm{m} / \mathrm{z} 554.2615$ and $[\mathrm{M}+\mathrm{H}]^{+} \mathrm{m} / \mathrm{z} 556.2771$ was 10,000 and 12,000 at FWHM, respectively. The ESI source parameters in nESI and pESI were: capillary voltage 1300 and $1175 \mathrm{~V}$, cone voltage 30 and $27 \mathrm{~V}$, source temperature $120^{\circ} \mathrm{C}$, desolvation temperature $450{ }^{\circ} \mathrm{C}$, cone gas flow $40 \mathrm{~L} \mathrm{~h}^{-1}$, desolvation gas flow 
Table 2

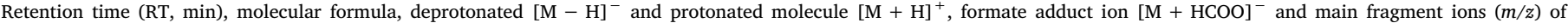
tentatively assigned furokauranes (F) and atractyligenins (A) in aqueous extracts of GC and CS.

\begin{tabular}{|c|c|c|c|c|c|c|}
\hline Peak & RT & Molecular formula & {$[\mathrm{M}-\mathrm{H}]^{-}$} & {$\left[\mathrm{M}+\mathrm{HCOO}^{-}\right.$} & {$\left[\mathrm{M}-\mathrm{H}-\mathrm{CO}_{2}\right]^{-}$} & {$[\mathrm{M}+\mathrm{H}]^{+}$} \\
\hline FU1-G ${ }^{\mathrm{a}}$ & 1.41 & $\mathrm{C}_{27} \mathrm{H}_{36} \mathrm{O}_{13}$ & - & 597.2183 & & \\
\hline F1-G $\mathrm{G}^{\mathrm{b}}$ & 1.90 & $\mathrm{C}_{26} \mathrm{H}_{36} \mathrm{O}_{11}$ & - & 569.2234 & & \\
\hline FU2-G ${ }^{c}$ & 1.99 & unknown & - & 559.2791 & & \\
\hline FU3-G ${ }^{\mathrm{d}}$ & 2.08 & unknown & - & 543.2740 & & \\
\hline A1 & 2.12 & $\mathrm{C}_{26} \mathrm{H}_{38} \mathrm{O}_{11}$ & 525.2336 & - & 481.2438 & \\
\hline $\mathrm{A} 2$ & 2.30 & $\mathrm{C}_{25} \mathrm{H}_{38} \mathrm{O}_{9}$ & 481.2438 & 527.2492 & & {$[\mathrm{M}+\mathrm{Na}]^{+} 505.2414$} \\
\hline $\mathrm{F} 2-\mathrm{G}^{\mathrm{e}}$ & 2.45 & $\mathrm{C}_{26} \mathrm{H}_{36} \mathrm{O}_{10}$ & - & 553.2285 & & \\
\hline FU $2^{f}$ & 2.62 & unknown & 351.2082 & 397.2319 & & \\
\hline $\mathrm{FU}^{\mathrm{g}}$ & 2.67 & unknown & 367.2165 & 413.2259 & & \\
\hline $\mathrm{F} 2^{\mathrm{h}}$ & 2.72 & $\mathrm{C}_{20} \mathrm{H}_{26} \mathrm{O}_{5}$ & - & 391.1757 & & \\
\hline A3 & 2.76 & $\mathrm{C}_{25} \mathrm{H}_{38} \mathrm{O}_{9}$ & 481.2438 & 527.2492 & & {$[\mathrm{M}+\mathrm{Na}]^{+} 505.2414$} \\
\hline A4 & 2.81 & $\mathrm{C}_{20} \mathrm{H}_{28} \mathrm{O}_{6}$ & 363.1808 & - & 319.1909 & 365.1964 \\
\hline A5 & 2.99 & $\mathrm{C}_{19} \mathrm{H}_{28} \mathrm{O}_{4}$ & 319.1909 & 365.1964 & 319.1909 & - \\
\hline A6 & 3.13 & $\mathrm{C}_{37} \mathrm{H}_{56} \mathrm{O}_{17}$ & 771.3439 & - & 727.3541 & {$[\mathrm{M}+\mathrm{Na}]^{+} 795.3415$} \\
\hline A7 & 3.21 & $\mathrm{C}_{37} \mathrm{H}_{56} \mathrm{O}_{17}$ & 771.3439 & - & 727.3541 & {$[\mathrm{M}+\mathrm{Na}]^{+} 795.3415$} \\
\hline A8 & 3.65 & $\mathrm{C}_{19} \mathrm{H}_{28} \mathrm{O}_{4}$ & 319.1909 & 365.1964 & & - \\
\hline A9 & 3.65 & Unknown & 609.2911 & - & 565.3013 & \\
\hline A10 & 3.81 & $\mathrm{C}_{36} \mathrm{H}_{56} \mathrm{O}_{15}$ & 727.3541 & 773.3596 & & {$[\mathrm{M}+\mathrm{Na}]^{+} 751.3517$} \\
\hline A11 & 4.14 & Unknown & 609.2911 & - & 565.3013 & {$[\mathrm{M}+\mathrm{Na}]^{+} 633.2887$} \\
\hline A12 & 4.57 & Unknown & 609.2911 & - & 565.3013 & {$[\mathrm{M}+\mathrm{Na}]^{+} 633.2887$} \\
\hline
\end{tabular}

${ }^{\text {a }}$ Unknown 1-glycoside (FU1-G).

${ }^{b}$ Furokaurane 1-glycoside, mascaroside (F1-G).

${ }^{c}$ Unknown 2-glycoside (FU2-G).

${ }^{\mathrm{d}}$ Unknown 3-glycoside (FU3-G).

e Furokaurane 2-glycoside, mozambioside (F2-G).

${ }^{f}$ Unknown 2 aglycone (FU2).

${ }^{g}$ Unknown 4 aglycone (FU4).

${ }^{\text {h }}$ Furokaurane 2 aglycone, mozambioside aglycone (F2).

$800 \mathrm{~L} \mathrm{~h}^{-1}$. Data acquisition, data handling and instrument control were performed by MassLynx Software 4.1v.

\subsection{Samples and calibration standards preparation for UHPLC-PDA-ESI- TOF/MS analysis}

CS and GC samples extracted as described in Section 2.2, were diluted $(1: 3, v / v)$ with mobile phase A:B $(95: 5, v / v)$, filtered $(0.22 \mu \mathrm{m}$, Millipore, Milan, Italy) and the filtrates transferred to vials for analysis ( $5 \mu \mathrm{L}$ injected). All the samples were analyzed in duplicate in two independent runs.

Standard solutions of CAF, CA, FA and 5-CQA were prepared in methanol at the concentration of $1 \mathrm{mg} \mathrm{mL}^{-1}$ and diluted $(1: 10, v / \mathrm{v})$ with mobile phase. Standard stock solutions of CAF and 5-CQA for quantitative analysis were prepared separately in methanol at the concentration of $1 \mathrm{mg} \mathrm{mL}^{-1}$ and stored at $4{ }^{\circ} \mathrm{C}$ as previously reported (Panusa et al., 2013). Working solutions of each standard at 5, 10, 20, 50 , and $100 \mu \mathrm{gL}^{-1}$ were prepared by diluting the stock solutions with the mobile phase A:B $(95: 5, v / v)$. Calibration samples were prepared in triplicate and analyzed in duplicate in two independent runs. Peak integration was performed at $\lambda=275 \mathrm{~nm}$ for CAF and at $\lambda=324 \mathrm{~nm}$ for all CGAs. Calibration curves of CAF and 5-CQA were calculated with equal weighted least-squares linear regression analysis of peak area against standard nominal concentration. The content of CGAs and CAF are the mean of two samples.

\section{Results and discussion}

\subsection{UHPLC-PDA-ESI-TOF/MS metabolic profiling}

CS-A, CS-R, CS-b, and GC were analyzed by UHPLC-PDA-ESI-TOF/ MS with a six-minute gradient, under the optimized experimental conditions previously developed (Panusa et al., 2013).

PDA chromatograms of all CS extracts were characterized by the predominant $\mathrm{CAF}$ peak at $\mathrm{RT}=1.20 \mathrm{~min}$, while 5-CQA peak at $\mathrm{RT}=1.13$ min was the main peak in GC (data not shown).
In order to investigate and to compare the phenolic fraction of GC and CS, PDA chromatograms were extracted at $\lambda=324 \mathrm{~nm}$, the characteristic absorption wavelength of CGAs.

Other metabolites, like furokauranes detected by both UV and MS spectrometry, and atractyligenins, investigated by MS spectrometry, are discussed in Sections 3.1.2 and 3.1.3, respectively.

Some metabolites were assigned by comparison of RT, monoisotopic mass, and UV spectra of reference compounds available and they can be regarded as level 1, identified compounds (Sumner et al., 2007); metabolites assigned without a reference standard, on the basis of accurate mass of protonated and deprotonated molecules, confirmed by isotopic distribution modeling, UV spectra and literature, must be regarded as level 2, tentatively assigned compounds (Sumner et al., 2007). For identified and tentatively assigned metabolites observed monoisotopic masses were within $25 \mathrm{ppm}$ from the theoretical values.

\subsubsection{CGAs}

The UV chromatograms $(\lambda=324 \mathrm{~nm})$ of GC, CS-R, CS-b and CS-A, are depicted in Fig. 1. Peaks identified with reference compounds i.e. 5CQA 5, CAF 6, CA 9, FA 16 and peaks tentatively assigned are all summarized in Table 1 . Compound $6\left(\lambda_{\max }=273 \mathrm{~nm}\right)$ is hardly detectable in Fig. 1 due to its low absorption at $\lambda=324 \mathrm{~nm}$.

As expected, the main difference between GC and CS is the abundance of CGAs, which is higher in GC than in CS (see Fig. 1). Furthermore, UV chromatograms of CS evidenced that CS-R is richer than CS-A in CGAs (Fig. 1b and d) consistently with literature on coffee (Moeenfard, Rocha, \& Alves, 2014; Tfouni et al., 2014). Moreover, 5 is the most abundant peak in GC while peak $7+8$ (4-CQA and feruloylquinic acid, FQA) is higher than $\mathbf{5}$ in all CS. The assignment of 3-CQA and 4-CQA is based on literature (Alves et al., 2010; Bresciani et al., 2014).

Chromatograms are consistent with chromatograms of CS-A and GC previously depicted (Regazzoni et al., 2016), although 9 (mainly detected in GC and in CS-R) was not previously reported as a CS metabolite. Also 16, detected only in CS (mainly in CS-R), was not previously observed in CS. Two other compounds tentatively assigned 
<smiles>CC12CC(=O)c3occc3C1CCC13CC(CC(O)(CO)C1)C2C(OC1OC(CO)C(O)C(O)C1O)C3</smiles>

1<smiles>C=C1C2CCC3C4(C)CC(O)CC(C(=O)O)(C(=O)O)C4CCC3(C2)C1O</smiles>

4<smiles>CC12CC(=O)c3occc3C1CCC13CCC(CC(O)C21)C(O)C3(O)COC1OC(CO)C(O)C(O)C1O</smiles>

2<smiles>C=C1C(O)C23CCC1C(C)(C2)C1CCC2C(C(=O)O)CC(OC4OC(CO)C(O)C(O)C4O)CC2(C)C1C3</smiles>

5<smiles>C=C1C2CCC3C4CCC2C3(CCC2C(C(=O)O)CC(O)CC24C)C1O</smiles>

3<smiles>C=C1C2CCC3C4(C)CC(OC5OC(CO)C(O)C(OC6OC(CO)C(O)C(O)C6O)C5OC(=O)CC(C)C)CC(C(=O)O)C4CCC3(C2)C1O</smiles>

7<smiles>C=C1C2CCC3C4(C)CC(OC5OC(CO)C(O)C(OC6OC(CO)C(O)C(O)C6O)C5OC(=O)CC(C)C)CC(C(=O)O)(C(=O)O)C4CCC3(C2)C1O</smiles>

8

Scheme 1. Molecular structures of compounds.

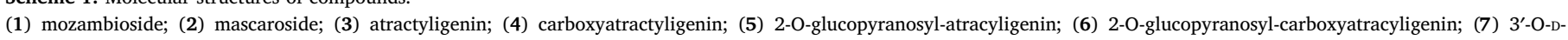
glucopyranosyl-2'-O-isovaleryl-2-(2-desoxy-atractyligenin)-D-glucopyranoside; (8); 3'-O-D-glucopyranosyl-2'-O-isovaleryl-2-(2-desoxy-carboxyatractyligenin)-D-glucopyranoside.

as dimethoxycinnamoylquinic acid isomers (di-MeCiQA, 15 and 17 $[\mathrm{M}-\mathrm{H}]^{-}$at $\left.m / z=381.1186\right)$ already detected in green robusta coffee beans, and dimethoxycinnamic acid (di-MeCiA, $21[\mathrm{M}-\mathrm{H}]^{-}$ at $m / z=207.0657$ ) were not previously reported in CS (Clifford, Knight, Surucu, \& Kuhnert, 2006; Jaiswal, Sovdat, Vivan, \& Kuhnert, 2010; Ross, 2005). As expected, caffeoylquiniclactones, which are supposed to be produced from caffeoylquinic acids during the roasting process, were hardly detected in our samples (Farah, De Paulis, Moreira, Trugo, \& Martin, 2006; Farah, De Paulis, Trugo, \& Martin, 2005) and are not visible in Fig. 1, consistently with literature (Regazzoni et al., 2016). Nevertheless, they were previously quantified at low level (Bresciani et al., 2014). Peaks 22 (caffeoyltrypthophan, CTF) and 23 (coumaroyl tryptophan, $\operatorname{CoTF}\left([\mathrm{M}-\mathrm{H}]^{-}\right.$at $\mathrm{m} /$ $z=349.1188$ ), not previously reported in CS, were detected only in CS-R (Alves et al., 2010).

Some peaks were not assigned and others, like F1-G and F2-G, although absorbing at $\lambda=324 \mathrm{~nm}$, were not CGAs as revealed by their UV spectra (see Fig. 2). Such peaks were tentatively assigned as furokauranes, as discussed in Section 3.1.2.

Briefly, peaks 1, 2, 3, 5 and 7 were recognized as CQA isomers with $[\mathrm{M}-\mathrm{H}]^{-}$at $m / z=353.0873$, while peak 4 was assigned as a coumaroylquinic acid isomer (CoQA, $\left[\mathrm{M}-\mathrm{H}^{-}\right.$at $m / z=337.0923$ ); two other isomers of CoQA (11 and 13) co-eluted with FQA, 10 and 12 $\left([\mathrm{M}-\mathrm{H}]^{-}\right.$at $\left.m / z=367.1029\right)$. Peaks 18, 19 and 20 were assigned as di-CQA isomers $\left([\mathrm{M}-\mathrm{H}]^{-}\right.$at $\left.m / z=515.1190\right)$, consistently with literature on CS-A (Bresciani et al., 2014; Regazzoni et al., 2016). In conclusion, the presence of peaks $2,3,5,7,9$ and 18, 19, 20 evidenced CA derivatives as the main CGAs in GC and CS.

\subsubsection{Furokauranes}

The Total Ion Chromatogram (TIC) of GC, CS-R, CS-b and CS-A, is displayed in Fig. 3. In all the chromatograms two regions can be 


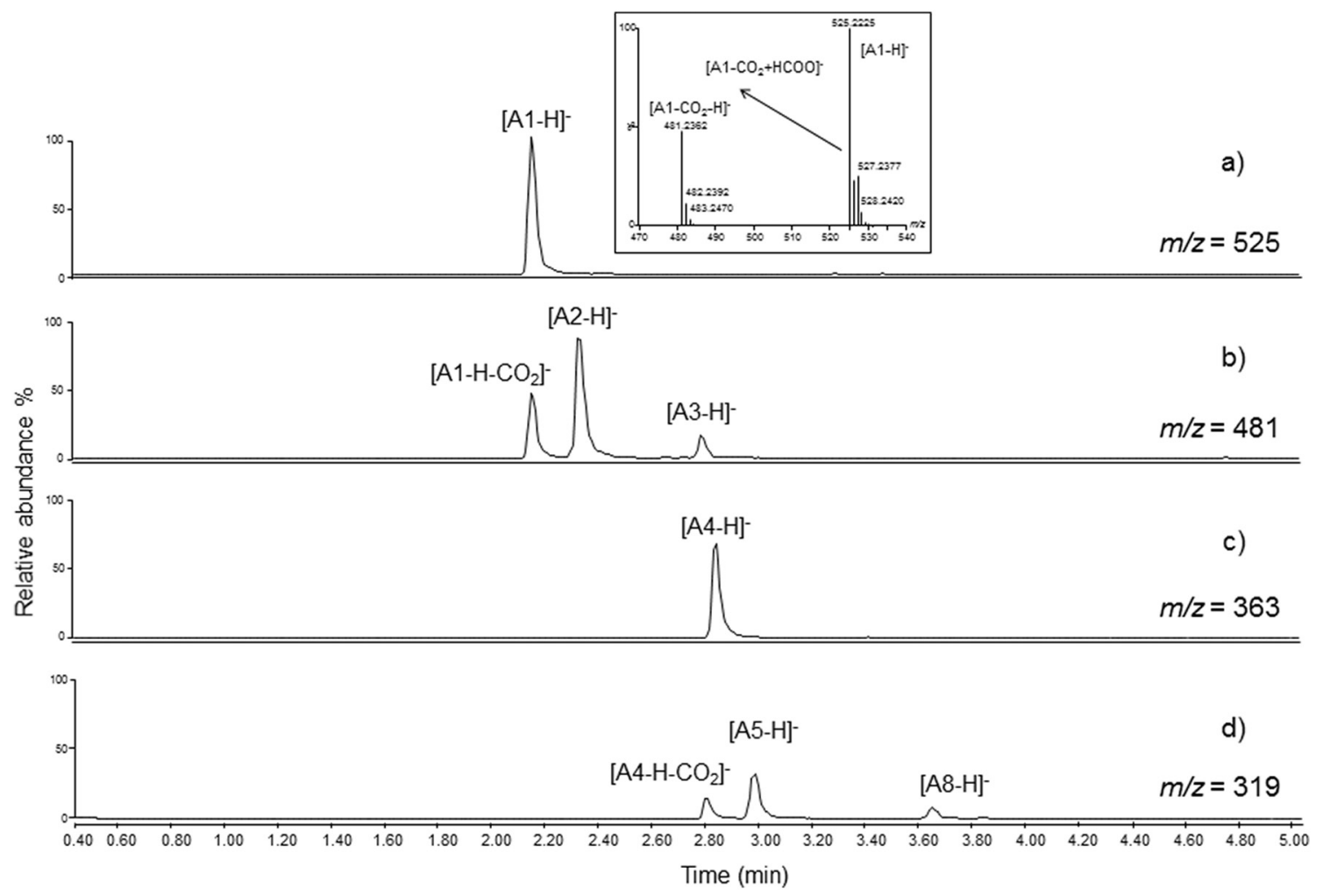

Fig. 4. Extracted ion chromatograms (EIC) of atractyligenins in CS-A extracts: a) A1; b) A2, A3; c) A4; d) A5, A8;

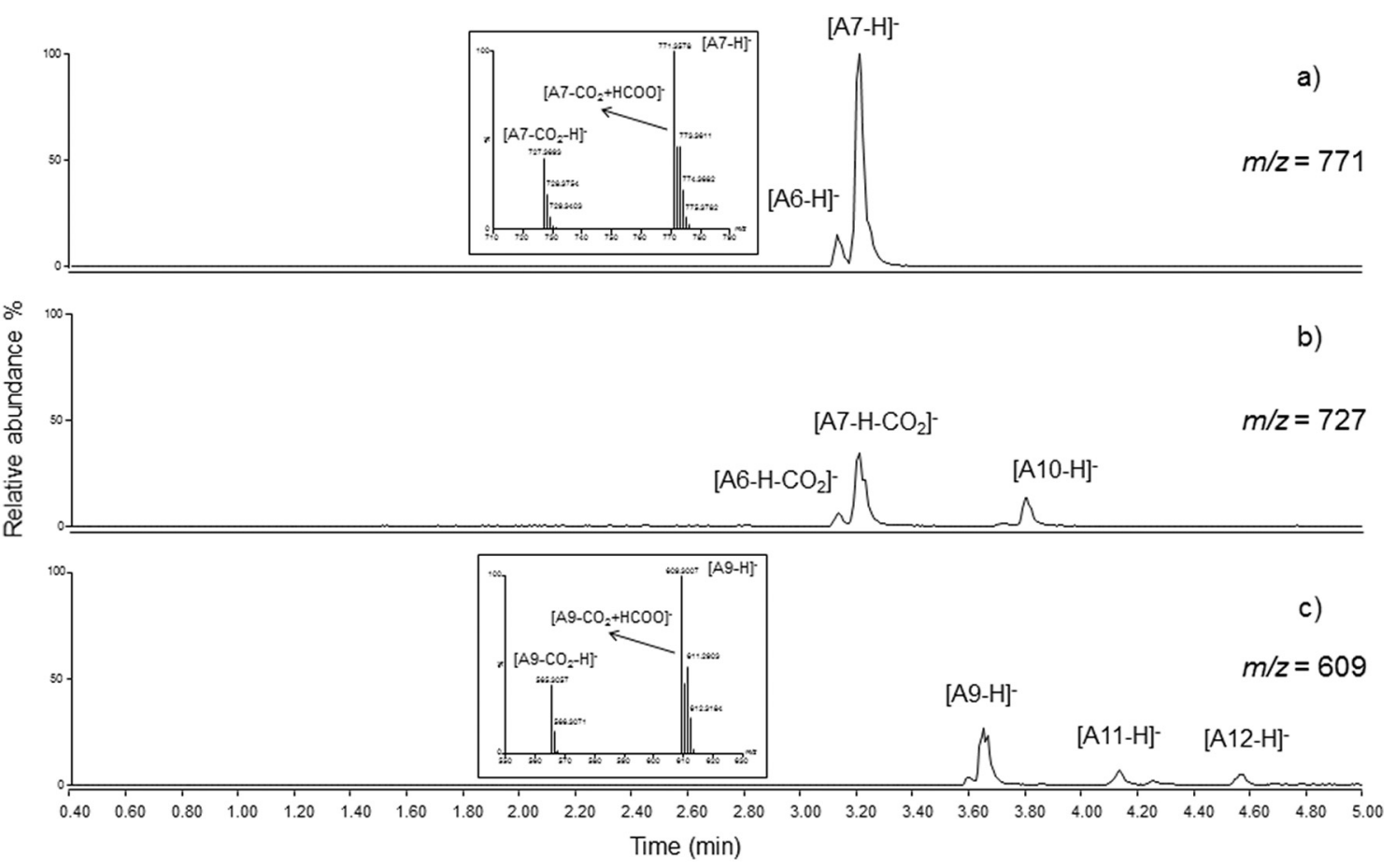

Fig. 5. Extracted ion chromatograms of atractyligenins in GC extracts: a) A6, A7; b) A10; c) A9; A11, A12;

distinguished. The first one (0-2.54 $\mathrm{min})$ is characterized by the elution of peaks approximately in the $500-600 \mathrm{~m} / \mathrm{z}$ range, while the second one, starting from $2.55 \mathrm{~min}$, is characterized by the presence of peaks in the $300-500 \mathrm{~m} / \mathrm{z}$ range. Some of the peaks at higher $\mathrm{m} / \mathrm{z}$ have been assigned to glycosides which aglycones are eluted in the second region of the chromatogram. This elution order is consistent with the RTs already observed for flavonoids and their glycosides (Panusa, Petrucci, Marrosu, Multari, \& Gallo, 2015).
Some of these peaks have been tentatively assigned either as diterpenoid glycosides of the furokaurane type or as their corresponding aglycones. Such identification was firstly done on the basis of a strong characteristic UV absorption band at approximately $\lambda=281 \mathrm{~nm}$ (Fig. 2) due to the furfural chromophore (Martinez, Rodriguez, York, Preston, \& Ingram, 2000). Three peaks at RT $=1.90,2.45$ and 2.72 min, namely, F1-G, F2-G and F2, showed this band.

The highest peak, F2-G (RT $=2.45 \mathrm{~min})$, evidenced as formate ion 
Table 3

Moisture content (MC), caffeine (CAF), chlorogenic acids (CGAs), total phenolics and antioxidant capacity (by DPPH, ABTS and FRAP methods) of GC and CS samples.

\begin{tabular}{|c|c|c|c|c|c|c|c|}
\hline Material & $\begin{array}{l}\text { MC } \\
(\%)\end{array}$ & $\begin{array}{l}\text { CAF } \\
(\mathrm{mg} / \mathrm{g})\end{array}$ & $\begin{array}{l}\mathrm{CGAs}^{\mathrm{a}} \\
(\mathrm{mg} \mathrm{CGA} / \mathrm{g})\end{array}$ & $\begin{array}{l}\text { Total phenolics } \\
\text { (mg GAE/g) }\end{array}$ & $\begin{array}{l}\mathrm{AA}_{\mathrm{DPPH}}{ }^{\mathrm{C}} \\
(\mathrm{mg} \mathrm{TE} / \mathrm{g})\end{array}$ & $\begin{array}{l}\mathrm{AA}_{\mathrm{ABTS}}{ }^{\mathrm{c}} \\
(\mathrm{mg} \mathrm{TE} / \mathrm{g})\end{array}$ & $\begin{array}{l}\mathrm{AA}_{\text {FRAP }}{ }^{\mathrm{c}} \\
(\mathrm{mg} \mathrm{TE} / \mathrm{g})\end{array}$ \\
\hline GC & 5.03 & $15.132 \pm 0.027$ & $72.938 \pm 0.129$ & $48.51 \pm 0.88$ & $45.79 \pm 0.60$ & $58.62 \pm 1.57$ & $54.61 \pm 1.47$ \\
\hline CS-A & 3.37 & $3.728 \pm 0.006$ & $0.266 \pm 0.002$ & $7.83 \pm 0.25$ & $6.73 \pm 0.05$ & $9.31 \pm 0.54$ & $10.19 \pm 0.01$ \\
\hline CS-R & 1.21 & $3.751 \pm 0.001$ & $1.247 \pm 0.004$ & $12.82 \pm 0.09$ & $9.15 \pm 0.11$ & $15.63 \pm 0.26$ & $14.53 \pm 0.36$ \\
\hline CS-b & 5.27 & $2.821 \pm 0.004$ & $0.202 \pm 0.001$ & $4.35 \pm 0.14$ & $4.03 \pm 0.13$ & $6.14 \pm 0.16$ & $4.81 \pm 0.07$ \\
\hline
\end{tabular}

${ }^{\text {a }}$ As 5-CQA equivalent.

${ }^{\mathrm{b}}$ As gallic acid equivalent (GAE).

c As Trolox equivalent (TE).

Table 4

Estimation of furokauranes in GC and $\mathrm{CS}^{\mathrm{a}}$ (mean of two samples).

\begin{tabular}{llll}
\hline & $\begin{array}{l}\text { Mascaroside } \\
(\mathrm{F} 1-\mathrm{G})\end{array}$ & $\begin{array}{l}\text { Mozambioside } \\
(\mathrm{F} 2-\mathrm{G})\end{array}$ & $\begin{array}{l}\text { Mozambioside aglycone } \\
(\mathrm{F} 2)\end{array}$ \\
\hline GC & 0.06 & 4.14 & 0.10 \\
CS-A & 0.58 & 4.40 & 0.15 \\
CS-R & 0.06 & 0.26 & 0.02 \\
CS-b & 0.46 & 2.02 & 0.18 \\
\hline
\end{tabular}

${ }^{\text {a }}$ Expressed as (total content of CGAs in the sample) / (MS total area of CGAs) $\times($ MS peak area of the compound).

$\left[\mathrm{M}+\mathrm{HCOO}^{-}\right.$at $m / z=553.2285$ (Table 2, UV spectrum in Fig. 2a), was tentatively assigned as mozambioside ( 1 in the Scheme 1 ), an arabica-specific bitter-tasting furokaurane glucoside identified for the first time in Coffee arabica (Richter \& Spiteller, 1979). The configuration of mozambioside was reported (Prewo, Guggisberg, Lorenziriatsch, Baumann, \& Wettsteinbattig, 1990) and this compound was lately detected by Anthony, Clifford, \& Noirot, 1993 who studied variations in biochemical composition of green coffee beans. Recently, mozambioside was detected in coffee beans with a characteristic absorption band at $280 \mathrm{~nm}$ (Lang, Klade, Beusch, Dunkel, \& Hofmann, 2015), while others evidenced its presence also in arabica roasted coffee (Shu et al., 2014). Peaks showing this characteristic band at $\lambda=281 \mathrm{~nm}$ were more intense in CS-A than in CS-R (Fig. 3), consistently with the literature on coffee (Lang et al., 2015). The assignment of mozambioside was supported by literature (Lang et al., 2015;Shu et al., 2014; Wishart et al., 2013). Moreover, mozambioside was suggested as an analytical marker for arabica coffee (Lang et al., 2015).

Peak F1-G (RT = $1.90 \mathrm{~min}$ ) was tentatively assigned as mascaroside (2 in the Scheme 1), which was firstly found in a coffee species from Madagascar (Ducruix, Pascard-Billy, Hammoniere, \& Poisson, 1975). It was evidenced in nESI as formate adduct ion $\left[\mathrm{M}+\mathrm{HCOO}^{-}\right.$at $\mathrm{m} /$ $z=569.2239$ (Table 2, UV spectrum in Fig. 2b). Also in this case the assignment was based on the literature on coffee (Shu et al., 2014; Wishart et al., 2013). The shorter RT of F1-G compared to F2-G is in agreement with the presence of an additional hydroxyl group in the chemical structure. Also mascaroside is a bitter-tasting compound and presumably replaces caffeine, as well as mozambioside, as natural plant defense, in some coffee species from East Africa (Prewo et al., 1990).

Peak F2 (RT $=2.68 \mathrm{~min}$ ) was tentatively assigned as mozambioside aglycone, evidenced as formate ion $[\mathrm{M}+\mathrm{HCOO}]^{-}$at $m / z=391.1757$ (Table 2, UV spectrum in Fig. 2c). Another evidence supporting this

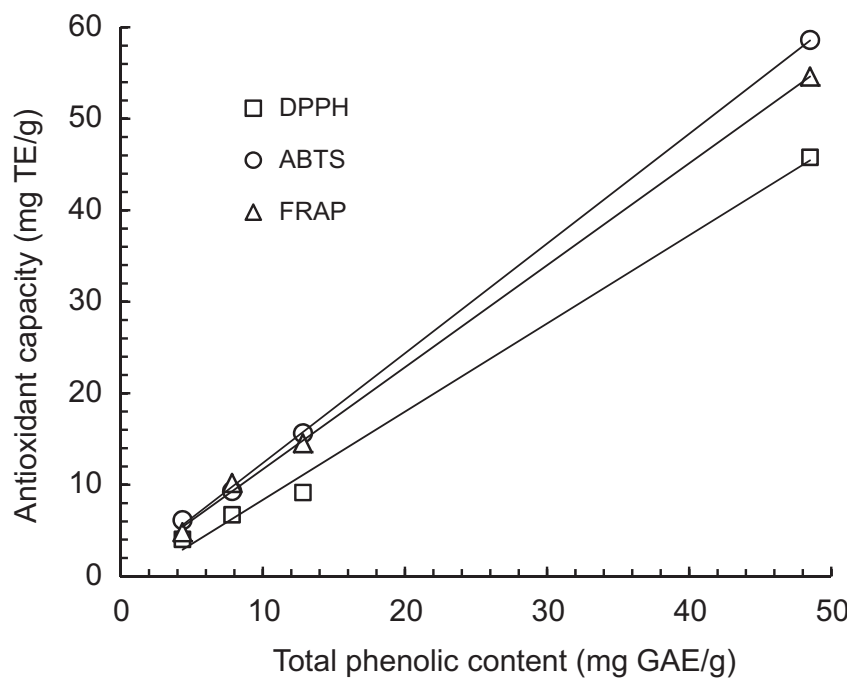

Fig. 6. Observed dependence of antioxidant capacity values determined by the three assays on the total phenolic content.

assignment is that the hydrolysis of mozambioside brought to the disappearance of the peak at $m / z=553.2285$ and to the increase of the peak at $m / z=391.1757$ (data not shown). To the best of our knowledge mozambioside aglycone has not been previously reported neither in CS nor in coffee.

Five peaks namely, $F_{U 1}-G, F_{U 2}-G, F_{U 3}-G, F_{U 2}$ and $F_{U 4}$ were not assigned, but some evidence suggests that they belong to the same furokaurane class of compounds and can be considered as level 3, unknown (Sumner et al., 2007).

Peak $\mathrm{F}_{\mathrm{U} 1}-\mathrm{G}$ at $m / z 597.1871(\mathrm{RT}=1.41 \mathrm{~min})$, showing a characteristic absorption at $\lambda=279 \mathrm{~nm}$ (Fig. 2d), is consistent with a carboxylic derivative of mozambioside; this hypothesis is supported by the $m / z$ difference between the two compounds ( $\Delta=43.978 \mathrm{Da})$ and by the shorter RT of $\mathrm{F}_{\mathrm{U} 1-\mathrm{G}}$ compared to F2-G.

Peaks $\mathrm{F}_{\mathrm{U} 2^{-}} \mathrm{G}(\mathrm{RT}=1.99 \mathrm{~min})$ with $\left[\mathrm{M}+\mathrm{HCOO}^{-}\right.$at 559.2791 and $\mathrm{F}_{\mathrm{U} 3}{ }^{-} \mathrm{G}(\mathrm{RT}=2.08 \mathrm{~min})$ with $\left[\mathrm{M}+\mathrm{HCOO}^{-}{ }^{-}\right.$at $543.2740 \mathrm{~m} / \mathrm{z}$ respectively, seem structurally related, like F1-G and F2-G $(\Delta=15.9947$ Da, consistent with a hydroxyl group). They also show the characteristic absorption at $\lambda=280 \mathrm{~nm}$, although less intense than F1-G and F2-G (Fig. 2e and f). The aglycone of $\mathrm{F}_{\mathrm{U} 2}-\mathrm{G}$, i.e. $\mathrm{F}_{\mathrm{U} 2}$ at $\mathrm{RT}=2.62 \mathrm{~min}$, is visible in the TIC chromatogram and in the mass spectrum is visible

Table 5

Estimation of atractyligenins in GC and $\mathrm{CS}^{\mathrm{a}}$ (mean of two samples).

\begin{tabular}{|c|c|c|c|c|c|c|c|c|c|c|c|c|}
\hline & $\mathrm{A} 1$ & A2 & A3 & A4 & A5 & A6 & A7 & A8 & A9 & A10 & A11 & A12 \\
\hline GC & 6.09 & 0.25 & n.d. & 0.12 & n.d. & 0.62 & 6.59 & n.d. & 2.03 & 0.58 & 0.64 & 0.57 \\
\hline CS-A & 1.37 & 1.33 & 0.22 & 0.98 & 0.55 & n.d. & n.d. & 0.12 & n.d. & 0.07 & n.d. & n.d. \\
\hline CS-R & 0.07 & 0.20 & 0.03 & 0.10 & 0.13 & n.d. & n.d. & 0.03 & n.d. & 0.01 & n.d. & n.d. \\
\hline CS-b & 0.41 & 0.55 & 0.09 & 0.85 & 0.61 & n.d. & n.d. & 0.13 & n.d. & 0.02 & n.d. & n.d. \\
\hline
\end{tabular}

${ }^{\text {a }}$ Expressed as (total content of CGAs in the sample) / (MS total area of CGAs) $\times($ MS peak area of the compound). 
both as formate ion at $m / z=397.2319$ and as deprotonated molecule, at $m / z=351.2082$. Another peak, $\mathrm{F}_{\mathrm{U} 4} \mathrm{RT}=2.67 \mathrm{~min}$, probably a derivative of $\mathrm{F}_{\mathrm{U} 2}(\Delta=16.002 \mathrm{Da})$, shows both $[\mathrm{M}-\mathrm{H}]^{-}$and $[\mathrm{M}$ $+\mathrm{HCOO}^{-}$ions at 367.2165 and $413.2259 \mathrm{~m} / \mathrm{z}$, respectively (Table 2 ). The presence of furokauranes in CS has not been reported in the literature before.

An estimation of the content of furokauranes in GC and CS is discussed in Section 3.2.

\subsubsection{Atractyligenins}

The presence of atractyligenins in coffee was firstly reported in the seventies and the content of these compounds, different in arabica and robusta varieties, was estimated (Maier \& Wewetzer, 1978). Atractyligenins are ent-kaurane diterpenoids (Kataev, Khaybullin, Sharipova, \& Strobykina, 2011) and in this study their presence in GC and CS has been investigated only by MS due to the lack of characteristic UV absorption bands in the $200-500 \mathrm{~nm}$ range. The tentative assignment of these compounds is based on the literature on coffee (Kucera, Papousek, Kurka, Bartak, \& Bednar, 2016; Lang et al., 2014), accurate mass measurement and isotopic distribution modeling in both nESI and pESI as reference compounds were not available.

The chemical structures of atractyligenins A1-A8 and A10 are shown in the Scheme 1 while in Table 2 are displayed, in elution order, retention time (RT), molecular formula, monoisotopic deprotonated $[\mathrm{M}-\mathrm{H}]^{-}$and protonated $[\mathrm{M}+\mathrm{H}]^{+}$molecules and main fragment ions. The EIC of atractyligenins (tolerance $\pm 0.05 \mathrm{Da}$ ) are shown in Figs. 4 and 5. In Fig. 4 they have been evidenced in CS-A due to their higher content in arabica than in robusta variety (as already evidenced in coffee). On the contrary, highly glycosilated atractyligenins are evidenced in GC (Fig. 5).

The EIC of atractyligenin (3 in the Scheme 1) with $[\mathrm{M}-\mathrm{H}]^{-}$ion at $=319.1909 \mathrm{~m} / \mathrm{z}$ gave rise to three isobaric peaks (Fig. 4d). Peaks A5 and A8 (RT $=2.99$ and $3.65 \mathrm{~min}$, respectively) have been tentatively assigned as two different isomers of atractyligenin 3, consistently with literature (Lang et al., 2013) while the peak at RT $=2.81 \mathrm{~min}$ has been assigned as the fragment ion of A4 (Fig. 4c) due to the neutral loss of $44 \mathrm{Da}\left(\mathrm{CO}_{2}\right.$ from carboxylic moiety). In MS spectra both A5 and A8 show a formate adduct at $365.1964 \mathrm{~m} / z$, while in pESI the loss of one and two molecules of water was also observed.

The EIC of carboxyatractyligenin (4 in the Scheme 1) at $[\mathrm{M}-\mathrm{H}]^{-}=363.1808 \mathrm{~m} / \mathrm{z}$ evidenced the intense peak A4 at $\mathrm{RT}=2.81 \mathrm{~min}$ (Fig. 4c). The formate adduct of carboxyatractyligenin (and of all the other carboxyatractyligenin derivatives) was not observed; this suggests that the presence of two carboxylic groups prevents its formation. As above mentioned, in the MS spectrum of peak A4 not only the characteristic loss of $44 \mathrm{Da}$ at $m / z 319.1909$ is evident, but also the formate adduct of this fragment ion at $m / z=365.1964$. In pESI beyond the protonated molecule $[\mathrm{M}+\mathrm{H}]^{+}=365.1964 \mathrm{~m} / z$, the fragment ions due to the loss of one and two molecules of water was also observed.

The EIC of 2-O- $\beta$-glucopyranosyl-atracyligenin ( 5 in the Scheme 1 ), at $[\mathrm{M}-\mathrm{H}]^{-}=481.2444 \mathrm{~m} / \mathrm{z}$, gave rise to three isobaric peaks (Fig. 4b); $\mathrm{A} 2$ and $\mathrm{A} 3$ (RT $=2.30$ and $2.76 \mathrm{~min}$, respectively) were tentatively assigned as two different isomers of 2-O- $\beta$-glucopyranosylatractyligenin, consistently with literature (Lang et al., 2013), while the peak at $\mathrm{RT}=2.12 \mathrm{~min}$ is the fragment ion of A1 due to the loss of $44 \mathrm{Da}$ (Fig. 4a). In the MS spectrum of peaks A2 and A3 the formate adducts at $m / z=527.2492$ were evident; in pESI the sodium adduct $[\mathrm{M}+\mathrm{Na}]^{+}=505.2414 \mathrm{~m} / \mathrm{z}$ was observed (Table 2 ).

The EIC of 2 -O- $\beta$-glucopyranosyl-carboxyatracyligenin (6 in the Scheme 1) at $[\mathrm{M}-\mathrm{H}]^{-}=525.2336 \mathrm{~m} / z$ evidenced an intense peak, A1 at RT $=2.12$ min (Fig. 4a) which characteristic loss of $44 \mathrm{Da}$ has been already evidenced in Fig. 4b.

As already observed in peak A1, also in this case no formate adduct was detected; the MS spectrum showed the fragment ion with the loss of $44 \mathrm{Da}$ at $m / z=481.2438$ and its formate adduct at $m / z=527.2492$; the simultaneous presence of $m / z=525.2336$ and $m / z=527.2492$ in the MS spectrum gave rise to a peculiar isotopic distribution (see the insert in Fig. 4a).

The EIC of 3 '-O- $\beta$-D-glucopyranosyl-2'-O-isovaleryl-2 $\beta$-(2-desoxyatractyligenin)- $\beta$-D-glucopyranoside ( 7 in the Scheme 1$)$ at $[\mathrm{M}-\mathrm{H}]^{-}=727.3541 \mathrm{~m} / \mathrm{z}$ gave rise to three isobaric peaks at $\mathrm{RT}=3.13, \quad 3.21$ and $3.81 \mathrm{~min}$, respectively (Fig. 5b). A10 $(\mathrm{RT}=3.81 \mathrm{~min})$ was tentatively assigned as $3^{\prime}-\mathrm{O}-\beta$-D-glucopyranosyl2 '-O-isovaleryl-2 $\beta$-(2-desoxy-atractyligenin)- $\beta$-D-glucopyranoside, while the other two peaks were assigned as the fragment ions of peaks A6 and A7, respectively, with the loss of $44 \mathrm{Da}$. Peak A10 showed the formate adduct at $m / z=773.3596$, while in pESI the sodium adduct was detected at $m / z=751.3517$ (Table 2).

The EIC of 3'-O- $\beta$-D-glucopyranosyl-2'-O-isovaleryl-2 $\beta$-(2-desoxycarboxyatractyligenin)- $\beta$-D-glucopyranoside ( 8 in the Scheme 1 ) at $[\mathrm{M}-\mathrm{H}]^{-}$at $=771.3439 \mathrm{~m} / \mathrm{z}$, evidenced peaks A6 and A7 at $\mathrm{RT}=3.13$ and $3.21 \mathrm{~min}$, respectively (Fig. 5a), which characteristic loss of $44 \mathrm{Da}$ has been already evidenced in Fig. 5b. In pESI the corresponding sodium adduct $[\mathrm{M}+\mathrm{Na}]^{+}$with $m / z=795.3415$ was observed (Table 2).

Peaks A9, A11 and A12 with $\mathrm{RT}=3.65,4.14$ and $4.57 \mathrm{~min}$, respectively, were evidenced as isobaric peaks at $m / z=609.2911$ (Fig. 5c) which were not previously described (Lang et al., 2013; Lang et al., 2014). The isotope distribution model of MassLynx software is consistent with the $\mathrm{C}_{31} \mathrm{H}_{45} \mathrm{O}_{12}$ deprotonated molecule (16 ppm error). The MS spectrum of such compounds (see the insert in Fig. $5 \mathrm{c}$ ) displays no formate adduct and an intense $\left[\mathrm{M}-\mathrm{H}-\mathrm{CO}_{2}\right]^{-}$fragment ion at $m / z=565.3013$ with the corresponding formate ion $\left[\mathrm{M}-\mathrm{CO}_{2}+\mathrm{HCOO}^{-}\right.$at $m / z=567.3169$ giving the characteristic isotopic distribution already described for compounds 4 and 6 . On the basis of the mass spectrum, these compounds can be regarded as level 3, unknown metabolites (Sumner et al., 2007) which chemical structure is compatible with a glucopyranosyl-isovaleryl-carboxyatractyligenin derivative.

The evidence that all carboxyatractyligenins eluted before the corresponding atractyligenins support the assignment of these compounds; in the same way, all glucopyranosyl derivatives were eluted before the corresponding aglycones.

The estimation of atractyligenins in all samples is discussed in Section 3.3.

\subsection{UHPLC-PDA quantification of CGAs and CAF}

All the peaks in Table 1 (with the exception of CAF) were integrated to calculate the total content of CGAs in each sample. The content of CAF and CGAs (as 5-CQA equivalent) which were quantified in GC, CSA, CS-b and CS-R aqueous extracts, is displayed in Table 3.

As expected, CGAs and CAF were much higher in GC (72.938 and $15.132 \mathrm{mg} / \mathrm{g}$, respectively) than in CS and higher in CS-R than in CS-A. While the amount of CAF in CS-A and CS-R $(3.728$ and $3.751 \mathrm{mg} / \mathrm{g}$, respectively) was comparable, CGAs were nearly six times higher in CS$\mathrm{R}$ than in CS-A. CS-b showed the lowest amount of CAF $(2.821 \mathrm{mg} / \mathrm{g})$ and CGAs $(0.0202 \mathrm{mg} / \mathrm{g})$ although this latter was comparable to the same amount in CS-A.

\subsection{Estimation of atractyligenin derivatives and furokauranes}

Due to the lack of analytical standards, only an estimation of the amount of furokauranes and atractyligenins, related to the content of CGAs, has been carried out. In detail, for each compound, the value has been calculated as (total content of CGAs in the sample)/(MS total area of CGAs) $\times$ (MS peak area of the compound). MS peaks were integrated after extracting the corresponding deprotonated molecular ion in nESI (tolerance $\pm 0.05 \mathrm{Da}$ ).

The estimation of furokauranes (Table 4) displayed that the highest content of F1-G, F2-G and F2 was observed in CS-A while the lowest in 
CS-R. The content in CS-b was intermediate and similar to CS-A. In particular, mozambioside was the most abundant furokaurane in both GC and CS and the higher content in Coffee arabica than in Coffee canephora var. robusta confirmed it as a marker of this species. Its aglycone was observed mainly in CS. The different content of mascaroside and mozambioside was particularly evident in GC.

The estimation of atractyligenins in GC and CS is summarized in Table 5.

All compounds, with the exception of A6, A7, A9, A11 and A12 were detected in all CS although far higher in CS-A than in CS-R, in agreement with literature reporting a great difference in the content of atractyligenin glycosides in the seeds of Coffea arabica compared to Coffea canephora var. robusta (Maier \& Wewetzer, 1978). Higher glycosilated atractyligenins i.e. A6, A7 and, A9, A11 A12 were detected only in GC. On the contrary, A3, A5 and A8 were not detected in GC.

In GC, A7 displayed the highest value followed by A1. The new observed compound, A9 detected only in GC, although less abundant than A1 and A7 was at least three times higher than the other atractyligenins.

In CS, atractyligenins were always higher in CS-A than in CS-R. In CS-b the content was intermediate with the exception of A5 and A8 which were higher than in CS-A.

$\mathrm{A} 1$, the compound with the highest toxicity, was detected not only in GC but also CS-A where it was the most abundant together with A2.

\subsection{Total phenolic content}

Total phenolic content of GC and CS samples are listed in Table 3. As expected, GC was significantly richer in total phenolics than CS. Furthermore, relatively large differences were observed among CS types.

The amount of total polyphenols in GC (48.51 mg GAE/g) was in line with those reported in previous studies. For example, different Arabica GC varieties from the Rio Minas region (Brazil) were investigated and values ranging from 31.65 to $32.78 \mathrm{mg} \mathrm{GAE} / \mathrm{g}$ were found (Odžaković, Džinić, Kukrić, \& Grujić, 2016). In another study on four Arabica GC varieties from Colombia, Brazil, Ethiopia and Kenya, total phenolic contents ranging from 51.3 to $56.8 \mathrm{mg}$ GAE/g were determined (Baeza, Sarria, Bravo, \& Mateos, 2016).

Regarding CS samples, the amount of total phenolics ranged from 4.35 to $12.82 \mathrm{mg} / \mathrm{GAE}$ g. The phenolic content of CS-R was about 1.5 times higher than that of CS-A, in accordance with the fact that Robusta coffee beans are richer in polyphenols, especially chlorogenic acids, than those of Arabica variety (Richelle, Tavazzi, \& Offord, 2001). The blended CS sample exhibited the lowest level of polyphenols, which is likely due to the characteristics of single coffee varieties used and the roasting conditions. In particular, it is known that the greater the severity of the roasting process, the larger the reduction in polyphenols content (Sulaiman, Moon, \& Shibamoto, 2011).

\subsection{Antioxidant capacity}

Results of the antioxidant capacity determined by the DPPH, ABTS and FRAP methods are shown in Table 3. The three assays gave different results, but they were highly correlated with each other $\left(\mathrm{R}^{2}>0.995\right)$ and provided the same rank order of antioxidant capacity: GC > CS-R > CS-A > CS-b. Such differences are commonly reported in the literature and attributed to the fact that these methods use different chromogenic redox reagents with different standard potentials (Apak et al., 2007). Measurements by the ABTS and FRAP methods were close to each other and slightly higher than those using the DPPH assay. Interestingly, by plotting the antioxidant capacity of the various samples against their corresponding total phenolic content (Fig. 6) a very good correlation $\left(R^{2}>0.995\right)$ was showed suggesting that phenolic compounds are the main responsible for the observed antioxidant capacity.

\subsection{Conclusions}

In this svtudy, CAF and chlorogenic acid were identified in CS and the presence of furokauranes and atractyligenins was evidenced for the first time. Other phenolic compounds, like caffeic and ferulic acids, dimethoxycinnamic acid, caffeoyl- and coumaroyltryptophan were also detected for the first time in CS.

The highest content of CGAs and CAF was observed in CS-R while in CS-b they exhibited the lowest value. These results were consistent with the values of total polyphenols and antioxidant capacity which were higher in CS-R than in CS-A and CS-b. Interestingly, an opposite trend was observed for the content of atractyligenins and furokauranes. In fact, they were both more abundant in CS-A than in CS-R. The presence of phytotoxins and the low amount of CGA, especially in CS-A pose the question if it is actually worth using CS as a food additive or a dietary supplement. Certainly, these uses need careful evaluation and further studies on the toxicity of CS are necessary to assess its suitability as a functional food ingredient.

\section{Funding}

This research did not receive any specific grant from funding agencies in the public, commercial, or not-for-profit-sectors.

\section{Acknowledgments}

We are grateful to Ian Phipps, service engineer, Waters S.p.A., for his precious technical support on UPLC-PDA-ESI-MS/TOF instrumentation and to Gianluca Maffei for his assistance in the preparation of coffee and silverskin extracts. We also thank the Italian MIUR (Ministero dell'Università e della Ricerca Scientifica e Tecnologica) for financial support.

\section{References}

Alves, R., Costa, A., Jerez, M., Casal, S., Sineiro, J., Nunez, M., \& Oliveira, B. (2010). Antiradical activity, phenolics profile, and hydroxymethylfurfural in espresso coffee: Influence of technological factors. Journal of Agricultural and Food Chemistry, 58(23), 12221-12229. http://dx.doi.org/10.1021/jf1031229.

Anthony, F., Clifford, M. N., \& Noirot, M. (1993). Biochemical diversity in the genus Coffea L.: Chlorogenic acids, caffeine and mozambioside contents. Genetic Resources and Crop Evolution, 40, 9.

Apak, R., Guclu, K., Demirata, B., Ozyurek, M., Celik, S., Bektasoglu, B., ... Ozyurt, D. (2007). Comparative evaluation of various total antioxidant capacity assays applied to phenolic compounds with the CUPRAC assay. Molecules, 12(7), 1496-1547. http:// dx.doi.org/10.3390/12071496.

Baeza, G., Sarria, B., Bravo, L., \& Mateos, R. (2016). Exhaustive qualitative LC-DAD-MSn analysis of arabica green coffee beans: Cinnamoyl-glycosides and cinnamoylshikimic acids as new polyphenols in green coffee. Journal of Agricultural and Food Chemistry, 64(51), 9663-9674. http://dx.doi.org/10.1021/acs.jafc.6b04022.

Borrelli, R., Esposito, F., Napolitano, A., Ritieni, A., \& Fogliano, V. (2004). Characterization of a new potential functional ingredient: Coffee silverskin. Journal of Agricultural and Food Chemistry, 52(5), 1338-1343. http://dx.doi.org/10.1021/ jf034974x.

Bresciani, L., Calani, L., Bruni, R., Brighenti, F., \& Del Rio, D. (2014). Phenolic composition, caffeine content and antioxidant capacity of coffee silverskin. Food Research International, 61, 196-201. http://dx.doi.org/10.1016/j.foodres.2013.10. 047.

Brezova, V., Slebodova, A., \& Stasko, A. (2009). Coffee as a source of antioxidants: An EPR study. Food Chemistry, 114(3), 859-868. http://dx.doi.org/10.1016/j.foodchem. 2008.10.025.

Choi, H., \& Curhan, G. (2007). Coffee, tea, and caffeine consumption and serum uric acid level: The Third National Health and Nutrition Examination Survey. Arthritis \& Rheumatism-Arthritis Care \& Research, 57(5), 816-821. http://dx.doi.org/ $10.1002 /$ art. 22762.

Clifford, M., Knight, S., Surucu, B., \& Kuhnert, N. (2006). Characterization by LC-MSn of four new classes of chlorogenic acids in green coffee beans: Dimethoxycinnamoylquinic acids, diferuloylquinic acids, caffeoyldimethoxycinnamoylquinic acids, and feruloyl-dimethoxycinnamoylquinic acids. Journal of Agricultural and Food Chemistry, 54(6), 1957-1969. http://dx.doi.org/10. 1021/jf0601665.

Conde, E., Cara, C., Moure, A., Ruiz, E., Castro, E., \& Dominguez, H. (2009). Antioxidant activity of the phenolic compounds released by hydrothermal treatments of olive tree pruning. Food Chemistry, 114(3), 806-812. http://dx.doi.org/10.1016/j.foodchem. 2008.10.017. 
Ducruix, A., Pascard-Billy, C., Hammoniere, M., \& Poisson, J. (1975). X-ray structure of mascaroside, a new bitter glycoside from coffee beans. Journal of the Chemical Society, Chemical Communications, 1. http://dx.doi.org/10.1039/C39750000396.

Farah, A., De Paulis, T., Trugo, L., \& Martin, P. (2005). Effect of roasting on the formation of chlorogenic acid lactones in coffee. Journal of Agricultural and Food Chemistry, 53(5), 1505-1513. http://dx.doi.org/10.1021/jf048701t.

Farah, A., De Paulis, T., Moreira, D., Trugo, L., \& Martin, P. (2006). Chlorogenic acids and lactones in regular and water-decaffeinated arabica coffees. Journal of Agricultural and Food Chemistry, 54(2), 374-381. http://dx.doi.org/10.1021/jf0518305.

Garcia-Serna, E., Martinez-Saez, N., Mesias, M., Morales, F., \& del Castillo, M. (2014). Use of coffee silverskin and stevia to improve the formulation of biscuits. Polish Journal of Food and Nutrition Sciences, 64(4), 243-251. http://dx.doi.org/10.2478/pjfns-20130024.

Iriondo-DeHond, A., Martorell, P., Genoves, S., Ramon, D., Stamatakis, K., Fresno, M., ... del Castillo, M. (2016). Coffee silverskin extract protects against accelerated aging caused by oxidative agents. Molecules, 21(6), http://dx.doi.org/10.3390/ molecules 21060721.

Jaiswal, R., Sovdat, T., Vivan, F., \& Kuhnert, N. (2010). Profiling and characterization by LC-MSn of the chlorogenic acids and hydroxycinnamoylshikimate esters in mate (Ilex paraguariensis). Journal of Agricultural and Food Chemistry, 58(9), 5471-5484. http:// dx.doi.org/10.1021/jf904537z.

Kataev, E. V., Khaybullin, R. N., Sharipova, R. R., \& Strobykina, I. Y. (2011). Review Journal of Chemistry, 1(2), 93-160. http://dx.doi.org/10.1134/S2079978011010043.

Kucera, L., Papousek, R., Kurka, O., Bartak, P., \& Bednar, P. (2016). Study of composition of espresso coffee prepared from various roast degrees of Coffea arabica L. coffee beans. Food Chemistry, 199, 727-735. http://dx.doi.org/10.1016/j.foodchem.2015. 12.080 .

Lang, R., Fromme, T., Beusch, A., Wahl, A., Klingenspor, M., \& Hofmann, T. (2013). 2-Obeta-D-Glucopyranosyl-carboxyatractyligenin from Coffea L. inhibits adenine nucleotide translocase in isolated mitochondria but is quantitatively degraded during coffee roasting. Phytochemistry, 93, 124-135. http://dx.doi.org/10.1016/j. phytochem.2013.03.022.

Lang, R., Fromme, T., Beusch, A., Lang, T., Klingenspor, M., \& Hofmann, T. (2014). Raw coffee based dietary supplements contain carboxyatractyligenin derivatives inhibiting mitochondrial adenine-nucleotide-translocase. Food and Chemical Toxicology, 70, 198-204. http://dx.doi.org/10.1016/j.fct.2014.05.017.

Lang, R., Klade, S., Beusch, A., Dunkel, A., \& Hofmann, T. (2015). Mozambioside is an arabica-specific bitter-tasting furokaurane glucoside in coffee beans. Journal of Agricultural and Food Chemistry, 63(48), 10492-10499. http://dx.doi.org/10.1021/ acs.jafc.5b04847.

Maier, H. G., \& Wewetzer, H. (1978). Determination of diterpene glycosides in coffee (author's transl). Zeitschrift für Lebensmittel-Untersuchung und -Forschung, 167(2), 105-107.

Martinez, A., Rodriguez, M., York, S., Preston, J., \& Ingram, L. (2000). Use of UV absorbance to monitor furans in dilute acid hydrolysates of biomass. Biotechnology Progress, 16(4), 637-641. http://dx.doi.org/10.1021/bp0000508.

Martinez-Saez, N., Ullate, M., Martin-Cabrejas, M., Martorell, P., Genoves, S., Ramon, D., \& del Castillo, M. (2014). A novel antioxidant beverage for body weight control based on coffee silverskin. Food Chemistry, 150, 227-234. http://dx.doi.org/10.1016/j. foodchem.2013.10.100.

Moeenfard, M., Rocha, L., \& Alves, A. (2014). Quantification of caffeoylquinic acids in coffee brews by HPLC-DAD. Journal of Analytical Methods in Chemistry. http://dx.doi. org $/ 10.1155 / 2014 / 965353$.

Mullen, W., Nemzer, B., Ou, B., Stalmach, A., Hunter, J., Clifford, M., \& Combet, E. (2011). The antioxidant and chlorogenic acid profiles of whole coffee fruits are influenced by the extraction procedures. Journal of Agricultural and Food Chemistry, 59(8), 3754-3762. http://dx.doi.org/10.1021/jf200122m.

Napolitano, A., Fogliano, V., Tafuri, A., \& Ritieni, A. (2007). Natural occurrence of ochratoxin a and antioxidant activities of green and roasted coffees and corresponding byproducts. Journal of Agricultural and Food Chemistry, 55(25), 10499-10504. http://dx.doi.org/10.1021/jf071959+ .

Narita, Y., \& Inouye, K. (2014). Review on utilization and composition of coffee silverskin. Food Research International, 61, 16-22. http://dx.doi.org/10.1016/j foodres.2014.01.023.

Odžaković, B., Džinić, N., Kukrić, Z., \& Grujić, S. (2016). Effect of roasting degree on the antioxidant activity of different Arabica coffee quality classes. Acta Sci. Pol. Technol. Aliment. 15(4), 409-417.

Panusa, A., Zuorro, A., Lavecchia, R., Marrosu, G., \& Petrucci, R. (2013). Recovery of natural antioxidants from spent coffee grounds. Journal of Agricultural and Food
Chemistry, 61(17), 4162-4168. http://dx.doi.org/10.1021/jf4005719.

Panusa, A., Petrucci, R., Marrosu, G., Multari, G., \& Gallo, F. (2015). UHPLC-PDA-ESITOF/MS metabolic profiling of Arctostaphylos pungens and Arctostaphylos uva-ursi. A comparative study of phenolic compounds from leaf methanolic extracts. Phytochemistry, 115, 79-88. http://dx.doi.org/10.1016/j.phytochem.2015.01.002.

Prewo, R., Guggisberg, A., Lorenziriatsch, A., Baumann, T., \& Wettsteinbattig, M. (1990). Crystal-structure of mozambioside, a diterpene glycoside of Coffea

Pseudozanguebariae. Phytochemistry, 29(3), 990-992. http://dx.doi.org/10.1016/ 0031-9422(90)80065-O.

Regazzoni, L., Saligari, F., Marinello, C., Rossoni, G., Aldini, G., Carini, M., \& Orioli, M. (2016). Coffee silver skin as a source of polyphenols: High resolution mass spectrometric profiling of components and antioxidant activity. Journal of Functional Foods, 20, 472-485. http://dx.doi.org/10.1016/j.jff.2015.11.027.

Richelle, M., Tavazzi, I., \& Offord, E. (2001). Comparison of the antioxidant activity of commonly consumed polyphenolic beverages (coffee, cocoa, and tea) prepared per cup serving. Journal of Agricultural and Food Chemistry, 49(7), 3438-3442. http://dx. doi.org/10.1021/jf0101410.

Richter, H., \& Spiteller, G. (1979). A new furokaurene glycoside from green coffee beans. Chemische Berichte, 4(112), 5.

Rodrigues, F., Palmeira-de-Oliveira, A., das Neves, J., Sarmento, B., Amaral, M., \& Oliveira, M. (2015). Coffee silverskin: A possible valuable cosmetic ingredient. Pharmaceutical Biology, 53(3), 386-394. http://dx.doi.org/10.3109/13880209.2014. 922589.

Rodrigues, F., Sarmento, B., Amaral, M., \& Oliveira, M. (2016). Exploring the antioxidant potentiality of two food by-products into a topical cream: Stability, in vitro and in vivo evaluation. Drug Development and Industrial Pharmacy, 42(6), 880-889. http:// dx.doi.org/10.3109/03639045.2015.1088865.

Ross, I. A. (2005). Medicinal plants of the world. Chemical constituents, traditional and modern medicinal uses. Humana Press.

Shu, Y., Liu, J., Peng, X., Wan, L., Zhou, L., Zhang, T., \& Qiu, M. (2014). Characterization of diterpenoid glucosides in roasted Puer coffee beans. Journal of Agricultural and Food Chemistry, 62(12), 2631-2637. http://dx.doi.org/10.1021/jf500788t.

Singleton, V., Orthofer, R., Lamuela-Raventos, R., \& Packer, L. (1999). Analysis of total phenols and other oxidation substrates and antioxidants by means of Folin-Ciocalteu reagent. Oxidants and Antioxidants, 299(Pt a), 152-178.

Sulaiman, S. F., Moon, J. K., \& Shibamoto, T. (2011). Investigation of optimum roasting conditions to obtain possible health benefit supplement, antioxidants from coffee beans. J Diet Suppl, 8(3), 293-310. http://dx.doi.org/10.3109/19390211.2011. 593618.

Sumner, L., Amberg, A., Barrett, D., Beale, M., Beger, R., Daykin, C., ... Viant, M. (2007). Proposed minimum reporting standards for chemical analysis. Metabolomics, 3(3), 211-221. http://dx.doi.org/10.1007/s11306-007-0082-2.

Tfouni, S., Carreiro, L., Teles, C., Furlani, R., Cipolli, K., \& Camargo, M. (2014). Caffeine and chlorogenic acids intake from coffee brew: Influence of roasting degree and brewing procedure. International Journal of Food Science and Technology, 49(3), 747-752.

Toschi, T., Cardenia, V., Bonaga, G., Mandrioli, M., \& Rodriguez-Estrada, M. (2014). Coffee silverskin: Characterization, possible uses, and safety aspects. Journal of Agricultural and Food Chemistry, 62(44), 10836-10844. http://dx.doi.org/10.1021/ jf503200z.

Vaclavik, L., Vaclavikova, M., Begley, T., Krynitsky, A., \& Rader, J. (2013). Determination of multiple mycotoxins in dietary supplements containing green coffee bean extracts using ultrahigh-performance liquid chromatography-tandem mass spectrometry (UHPLC-MS/MS). Journal of Agricultural and Food Chemistry, 61(20), 4822-4830. http://dx.doi.org/10.1021/jf401139u.

Vignoli, J., Bassoli, D., \& Benassi, M. (2011). Antioxidant activity, polyphenols, caffeine and melanoidins in soluble coffee: The influence of processing conditions and raw material. Food Chemistry, 124(3), 863-868. http://dx.doi.org/10.1016/j.foodchem. 2010.07.008.

Wishart, D., Jewison, T., Guo, A., Wilson, M., Knox, C., Liu, Y., ... Scalbert, A. (2013). HMDB 3.0-The human metabolome database in 2013. Nucleic Acids Research, 41(D1), D801-D807. http://dx.doi.org/10.1093/nar/gks1065.

Zuorro, A. (2015). Optimization of polyphenol recovery from espresso coffee residues using factorial design and response surface methodology. Separation and Purification Technology, 152, 64-69. http://dx.doi.org/10.1016/j.seppur.2015.08.016.

Zuorro, A., \& Lavecchia, R. (2012). Spent coffee grounds as a valuable source of phenolic compounds and bioenergy. Journal of Cleaner Production, 34, 49-56. http://dx.doi. org/10.1016/j.jclepro.2011.12.003. 